\title{
Synergistic effect between Gum Exudates of Eucalyptus globles and 2,6-diphenyl-3-methylpiperidin-4-one on Corrosion Inhibition of MS in $1 \mathrm{~N} \mathrm{HCl}$
}

\author{
DHEENADHAYALAN S ${ }^{1}$, ROJA ${ }^{2}$, NIJARUBINI $V^{3}$ and MALLIKA $\mathrm{J}^{1 *}$ \\ 1,1*,2 Department of Chemistry, PSG College of Arts and Science, Coimbatore 641014, India. \\ ${ }^{3}$ Department of Chemistry, Dr. N.G.P Arts and Science College, Coimbatore 641048, India. \\ ${ }^{*}$ Corresponding author E-mail: jmchempsg2016@gmail.com
}

http://dx.doi.org/10.13005/ojc/340545

(Received: May 05, 2018; Accepted: August 19, 2018)

\begin{abstract}
Gum exudates of Eucalyptus globles (GEG) was identified as green inhibitor for MS dissolution in $1 \mathrm{~N} \mathrm{HCl}$ using gravimetric method at 303-323K. Efficiency of GEG was synergistically increased with addition of 2,6-diphenyl-3methyl-piperidin-4-one (3MDPP). The binary combination of GEG and 3MDPP shows maximum inhibition potency and their $\mathrm{S}_{\theta}$ value is $>1$ indicating that synergism exists between GEG and 3MDPP. Mechanism of inhibition of inhibitors on MS is physisorption and it obeys Langmuir's isotherm. Polarization and impedance measurements confirm that inhibitors act as mixed type.
\end{abstract}

Keywords: 3MDPP, GEG, Binary mixture, Mild steel, Synergism.

\section{INTRODUCTION}

In many industries corrosion is a major problem for materials during acid pickling or chemical cleaning. Recently plant gum exudates are found to be non-toxic green corrosion inhibitors for various metals in different media due to its good adhesive and polymeric nature ${ }^{1-13}$. These exudates protect the metal surfaces by adsorption through physical or chemical bonding. But inhibition performance and stability of these gum exudates are found to be less significant at higher temperature. Some researchers use metal cations and halide ions as external additive to enhance their inhibition performance ${ }^{14,15}$.
A thorough survey of literature reveals that, no work has so far been done on the influence of organic compounds as synergist for corrosion inhibition behavior of plant gum exudates and also their stability. So the present work aims to study the corrosion inhibition properties of gum exudates of Eucalyptus globles (GEG) towards the corrosion of $\mathrm{MS}$ in $1 \mathrm{~N} \mathrm{HCl}$ at $303-323 \mathrm{~K}$ for $1 \mathrm{~h}$, immersion period. At higher temperature the stability and efficiency of GEG was enhanced by addition of external synergist (3MDPP). In acidic medium, 3MDPP act as very good corrosion inhibitor ${ }^{16}$. Therefore the influence of 3MDPP on the inhibition character of GEG towards MS is studied in $1 \mathrm{~N} \mathrm{HCl}$ at $303-323 \mathrm{~K}$. Because 
binary combination of GEG and 3MDPP system exhibits excellent inhibition potency than individual components and also this mixture completely control or reduce the rate of dissolution of MS even at very higher temperature.

\section{Methodology}

The gum exudates of Eucalyptus globles (GEG) was collected in local area of Nilgiri in Tamil nadu, India. The collected gum is purified following the reported procedure ${ }^{17}$. The GEG solution was prepared with distilled water. The 3MDPP was synthesized using the reported procedures ${ }^{18,19}$. Laboratory grade $\mathrm{HCl}$ was used as an aggressive medium. The composition of $\mathrm{C}, \mathrm{Mn}, \mathrm{P}$ and $\mathrm{S}$ in the MS (\%wt) are $0.2,1.0,0.25$ and 0.025 respectively. The MS coupons of dimensions of $25 \times 10 \times 1 \mathrm{~mm}$ were used for the present study, following ASTM practice standard G-31 procedure ${ }^{20}$. The corrosion parameters are derived using equation(1-3).

Corrosion rate $(\mathrm{mmpy})=87.6 \times \frac{\mathrm{W}}{\rho \mathrm{At}}$

Inhibition efficiency $(\%)=\frac{\mathrm{W}_{0}-\mathrm{W}_{\mathrm{i}}}{\mathrm{W}_{0}} \times 100$

Surface Coverage $\quad \theta=1-\frac{\mathrm{W}_{\mathrm{i}}}{\mathrm{W}_{\mathrm{o}}}$

Where, $\mathrm{W}, \rho, \mathrm{A}, \mathrm{t}, \mathrm{W}_{\mathrm{o}}$ and $\mathrm{W}_{\mathrm{i}}$ represents mass loss $(\mathrm{g})$, density of MS $\left(\mathrm{gcm}^{-3}\right)$, area of the coupon $\left(\mathrm{cm}^{2}\right)$, immersion time $(\mathrm{h})$, weight loss of MS without and with inhibitor respectively.

A conventional three electrode assembly is taken for polarization and impedance studies. The experiment is performed with $100 \mathrm{ml}$ of test solution at $30^{\circ} \mathrm{C}$. A SCE, platinum and MS were used as reference, counter and working electrodes respectively. The scan rate and potential range of $1 \mathrm{mVs}^{-1}$ and +200 to $-200 \mathrm{mV}$ were employed. Extrapolation method was used to measure the corrosion current and potential. Inhibition potency was determined using equation 4 .

Inhibition potency $=\left(\mathrm{i}_{\text {corr }}^{\circ}-\mathrm{i}_{\text {corr }}\right) / \mathrm{i}_{\text {corr }}^{\circ} \times 100$

Where, $\mathrm{i}_{\text {corr }}$ and $\mathrm{i}_{\text {corr }}$ are the corrosion current density in the absence and presence of inhibitor.
Impedance data were derived in the frequency range of $10^{-1} \times 10^{-5} \mathrm{KHz}$ at OCP employing $10 \mathrm{mV}$ amplitudes of $A C$ signal. $Z_{\text {view }}$ software was used to obtain $R_{c t}$ and $C_{d l}$ values. The values of $R_{c t}$ are used to calculate inhibition potency by employing equation 5 .

Inhibition potency $=\left(\mathrm{R}_{\mathrm{ct}}-\mathrm{R}_{\mathrm{ct}}{ }_{\mathrm{ct}}\right) / \mathrm{R}_{\mathrm{ct}} \mathrm{X} 100$

Where, $\mathrm{R}_{\mathrm{ct}}$ and $\mathrm{R}_{\mathrm{ct}}^{\circ}$ are the charge transfer resistance with and without inhibitor.

\section{RESULT AND DISCUSSION}

\section{Effect of GEG}

The inhibition parameters studied (303$323 \mathrm{~K})$ for $\mathrm{GEG}$ towards $\mathrm{MS}$ in $1 \mathrm{~N} \mathrm{HCl}$ medium clearly reveal that GEG controls the MS dissolution (Table 1). The inhibiting potency of GEG on MS in $1 \mathrm{~N} \mathrm{HCl}$ directly varies with its concentration and it is mainly due to presence of carbohydrate, protein and polyphenols. These molecules are electrochemically active and interact with the MS surface through their labile electrons resulting in the development of film on MS surface. At higher temperature the inhibition efficiency of GEG decreases. This may be due to rapid movement of $\mathrm{HCl}$ molecules towards the $\mathrm{MS}$ surface and thus detaches the GEG molecules from the surface.

\section{Effect of 3MDPP}

The corrosion inhibiting ability of 3MDPP at room temperature directly varies with its concentration (Table 1). The carbonyl group and ring nitrogen in 3MDPP are probable groups that are able to form protective film on the MS. The simultaneous involvement of carbonyl group and ring nitrogen cannot be taken into account because it would be possible only through the attainment of boat conformation which is highly strained and 3MDPP exist in chair conformation ${ }^{21}$. Among the two anchoring site, the ring nitrogen is the most probable one due to its less electronegativity. At higher temperature, desorption of 3MDPP from the MS surface occurs causing a decrease in inhibition potency.

\section{Synergistic influence of 3MDPP on GEG}

The binary combination of GEG and 3MDPP acts as efficient inhibitor for MS in $1 \mathrm{~N} \mathrm{HCl}$. The increasing potency of binary mixture may be due to synergism existing between GEG and 3MDPP. 
The value of $S_{\theta}$ is evaluated using the relationship given by Aramaki ${ }^{22}$. The values of $S \theta$ are $>1$ for all studied combinations indicating the pronounced inhibition potency resulting from the injection of 3MDPP to GEG in testing solution (Table 1). The inhibition nature of the binary mixture is higher than the individual components and stable up to $323 \mathrm{~K}$. This can be explained as follows: The non bonding electrons present on the ring nitrogen atom of 3MDPP act as nucleophile. In acidic medium the positively charged metal surface attracts the non bonding electrons of 3MDPP towards itself. The adsorbed 3MDPP molecules on the metal surface act as intermediate bridge between MS surface and GEG. The adsorbed 3MDPP molecule holds the GEG through the several hydrogen bonds formed between carbonyl group of 3MDPP and phenolic/ hydroxyl/carboxyl groups of GEG and hence prevent the outward movement/ desorption of 3MDPP and the metal dissolution.

\section{Thermodynamic and Kinetics studies}

The mechanism of adsorption process of any molecule can be predicted with the help of Arrhenius (6) and Transition state (7) equations.

$\log \mathrm{CR}=\log \mathrm{A}-\frac{\mathrm{E}_{\mathrm{a}}^{*}}{2.303 \mathrm{RT}}$

Where, CR, A, $\mathrm{E}_{\mathrm{a}}{ }^{*}, \mathrm{R}$ and $\mathrm{T}$ represents corrosion rate, frequency factor, activation energy, universal gas constant and absolute temperature respectively. The plot of (log CR) vs $(1000 / T)$ (Fig. 1) forms a straight line with the slope $\left(-\mathrm{E}_{\mathrm{a}}{ }^{*} / 2.303\right.$ $R)$ from which the values $E_{a}{ }^{*}$ can be calculated (Table 2). The values of $\Delta \mathrm{H}^{\star}$ and $\Delta \mathrm{S}^{\star}$ are calculated using equation (7).

$\mathrm{CR}=\left(\frac{\mathrm{RT}}{\mathrm{Nh}}\right) \exp \left(\frac{\Delta \mathrm{S}^{*}}{\mathrm{R}}\right) \exp \left(\frac{-\Delta \mathrm{H}^{*}}{\mathrm{RT}}\right)$

Where, $\mathrm{N}, \mathrm{h}, \Delta \mathrm{S}^{*}$ and $\Delta \mathrm{H}^{*}$ represents the Avogadro's number, Planck's constant, entropy of activation and enthalpy of activation respectively. A straight line with slope $\left(-\Delta \mathrm{H}^{*} / 2.303 \mathrm{R}\right)$ and intercept $\left[\log (\mathrm{R} / \mathrm{Nh})+\left(\Delta \mathrm{S}^{*} / 2.303 \mathrm{R}\right)\right]$ is obtained by plotting log (CR/T) vs (1000/T) (Fig. 2). The values of $\Delta H^{*}$ and $\Delta S^{*}$ are calculated and included in the Table (2). The values of $\mathrm{E}_{\mathrm{a}}{ }^{*}$ and $\Delta \mathrm{H}^{*}$ for GEG, 3MDPP and binary mixture are much higher than blank (Table 2) which indicates physisorption. The positive sign of $\Delta \mathrm{H}^{*}$ reflect the endothermic nature of MS dissolution. The negative sign of $\Delta S^{*}$ for both systems confirms the decrease in disorderness during the conversion of reactant to activated complex which is the rate determining step ${ }^{23}$.
Table 1: Corrosion parameters for GEG, 3MDPP and binary mixture on $\mathrm{MS}$ in $1 \mathrm{~N} \mathrm{HCl}$

\begin{tabular}{|c|c|c|c|c|c|}
\hline \multirow[t]{2}{*}{$\mathrm{T}(\mathrm{K})$} & \multicolumn{2}{|c|}{ C (ppm) } & \multirow[t]{2}{*}{ I E (\%) } & \multirow[t]{2}{*}{ CR (mmpy) } & \multirow[t]{2}{*}{$\mathrm{S}_{\theta}$} \\
\hline & GEG & 3MDPP & & & \\
\hline \multirow[t]{14}{*}{303} & Blank & & & 0.082 & - \\
\hline & 10 & - & 14.29 & 0.0703 & - \\
\hline & 50 & - & 25.81 & 0.0609 & - \\
\hline & 100 & - & 32.26 & 0.0556 & - \\
\hline & 150 & - & 36.41 & 0.0522 & - \\
\hline & 200 & - & 42.4 & 0.0473 & - \\
\hline & - & 50 & 41.94 & 0.0476 & - \\
\hline & - & 250 & 56.22 & 0.0359 & - \\
\hline & - & 500 & 75.58 & 0.02 & - \\
\hline & - & 750 & 81.11 & 0.0155 & - \\
\hline & 50 & 50 & 64.06 & 0.0295 & 1.06 \\
\hline & 50 & 250 & 79.26 & 0.017 & 1.04 \\
\hline & 50 & 500 & 84.79 & 0.0125 & 1.2 \\
\hline & 50 & 750 & 90.78 & 0.0076 & 1.18 \\
\hline \multirow[t]{14}{*}{313} & Blank & & & 0.1652 & - \\
\hline & 10 & - & 12.36 & 0.1448 & - \\
\hline & 50 & - & 21.74 & 0.1293 & - \\
\hline & 100 & - & 29.52 & 0.1164 & - \\
\hline & 150 & - & 34.1 & 0.1089 & - \\
\hline & 200 & - & 39.13 & 0.1006 & - \\
\hline & - & 50 & 36.38 & 0.1051 & - \\
\hline & - & 250 & 53.32 & 0.0771 & - \\
\hline & - & 500 & 66.82 & 0.0548 & - \\
\hline & - & 750 & 79.18 & 0.0344 & - \\
\hline & 50 & 50 & 59.27 & 0.0673 & 0.98 \\
\hline & 50 & 250 & 80.09 & 0.0329 & 0.94 \\
\hline & 50 & 500 & 83.98 & 0.0265 & 1.06 \\
\hline & 50 & 750 & 87.87 & 0.02 & 1.15 \\
\hline \multirow[t]{14}{*}{323} & Blank & & & 0.2446 & - \\
\hline & 10 & - & 10.97 & 0.1644 & - \\
\hline & 50 & - & 19.17 & 0.1263 & - \\
\hline & 100 & - & 25.5 & 0.0866 & - \\
\hline & 150 & - & 26.12 & 0.0541 & - \\
\hline & 200 & - & 30.14 & 0.2178 & - \\
\hline & - & 50 & 32.77 & 0.1977 & - \\
\hline & - & 250 & 48.38 & 0.1822 & - \\
\hline & - & 500 & 64.61 & 0.1807 & - \\
\hline & - & 750 & 77.9 & 0.1709 & - \\
\hline & 50 & 50 & 50.7 & 0.1206 & 1.02 \\
\hline & 50 & 250 & 69.55 & 0.0745 & 0.97 \\
\hline & 50 & 500 & 81.14 & 0.0461 & 1.03 \\
\hline & 50 & 750 & 82.84 & 0.042 & 1.17 \\
\hline
\end{tabular}


Table 2: Activation parameters for GEG, 3MDPP and binary mixture on $M S$ in $1 \mathrm{~N} \mathrm{HCl}$

\begin{tabular}{|c|c|c|c|c|}
\hline Inhibitor & C (ppm) & $\mathrm{E}_{\mathrm{a}}{ }^{*}\left(\mathrm{~kJ} \mathrm{~mol}^{-1}\right)$ & $\Delta \mathrm{H}^{*}\left(\mathrm{~kJ} \mathrm{~mol}{ }^{-1}\right)$ & $-\Delta \mathrm{S}^{*}\left(\mathrm{~J} \mathrm{~mol}^{-1}\right)$ \\
\hline \multirow[t]{6}{*}{ GEG } & Blank & 44.57 & 41.97 & 127 \\
\hline & 10 & 46.12 & 43.52 & 123.17 \\
\hline & 50 & 48.07 & 45.47 & 117.91 \\
\hline & 100 & 48.43 & 45.83 & 117.52 \\
\hline & 150 & 50.64 & 48.03 & 110.86 \\
\hline & 200 & 52.38 & 49.78 & 105.92 \\
\hline \multirow[t]{4}{*}{ 3MDPP } & 50 & 50.55 & 47.95 & 111.74 \\
\hline & 250 & 51.26 & 48.66 & 111.85 \\
\hline & 500 & 59.77 & 57.17 & 88.26 \\
\hline & 750 & 50.97 & 48.37 & 119.7 \\
\hline \multirow[t]{4}{*}{ Binary mixture } & $50+50$ & 57.4 & 54.8 & 93.27 \\
\hline & $50+250$ & 59.99 & 57.39 & 89.82 \\
\hline & $50+500$ & 53.27 & 50.67 & 114.1 \\
\hline & $50+750$ & 69.82 & 67.21 & 63.63 \\
\hline
\end{tabular}
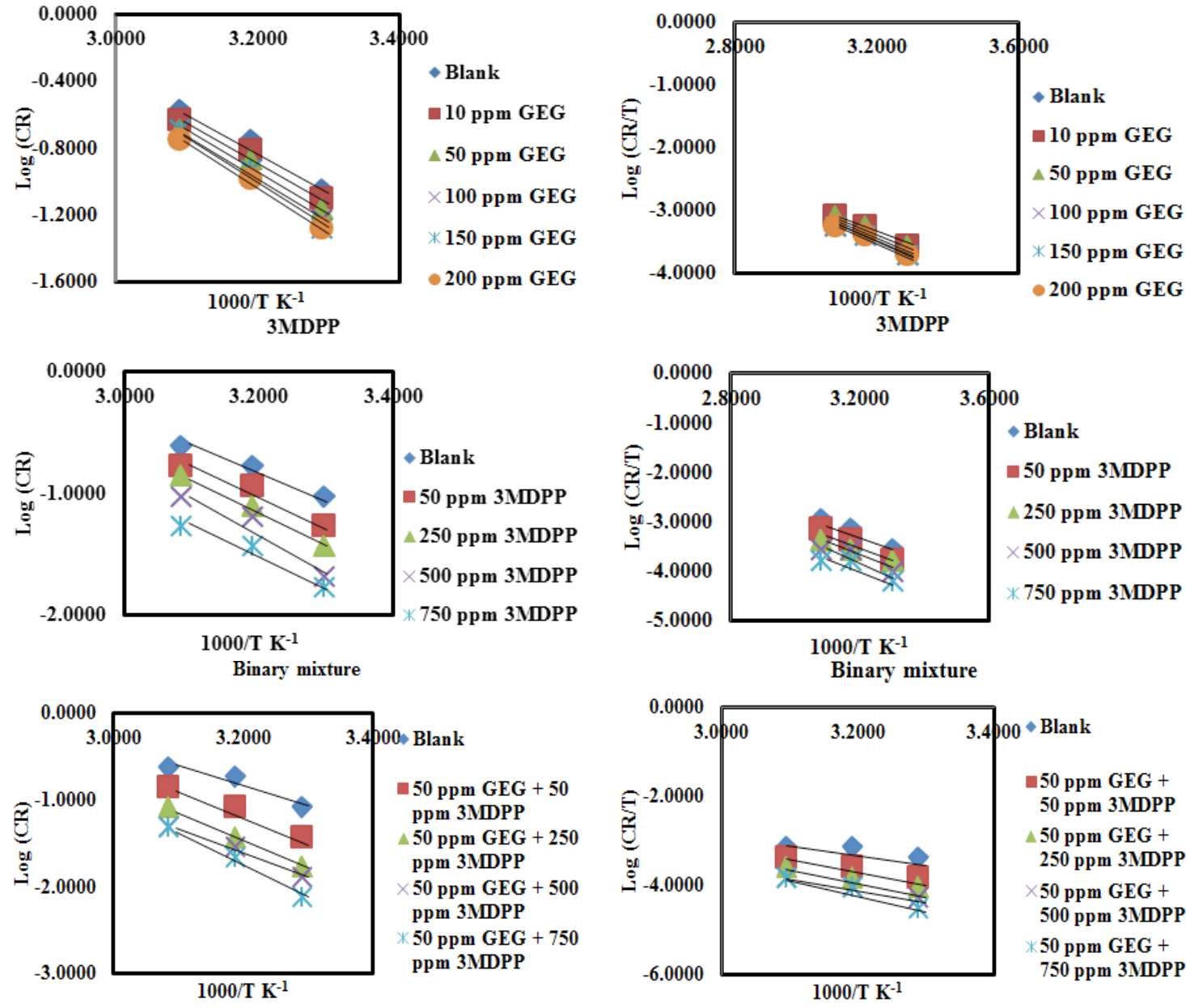

Fig. 1. Arrhenius plots for GEG, 3MDPP and binary mixture on $\mathrm{MS}$ in $1 \mathrm{~N} \mathrm{HCl}$

Fig. 2. Transition plots for GEG, 3MDPP and binary mixture on $\mathrm{MS}$ in $1 \mathrm{~N} \mathrm{HCl}$ 


\section{Adsorption Isotherm}

Adsorption of an inhibitor onto the metal surface in acidic medium depends on structure and conformation of inhibiting molecule, electrochemical potential on the metal and temperature of the medium. The mechanism of adsorption can be predicted by using Henry, Frendlich, Langmuir, Frumkin, and Temkin isotherm etc. Langmuir's isotherm is found to be the best description for present study and it is given by

$$
\frac{C}{\theta}=\frac{1}{\mathrm{~K}_{\mathrm{ads}}}+C
$$

Where, $\mathrm{K}_{\text {ads }}$ is the equilibrium constant. The $\left(\Delta \mathrm{G}^{\circ}{ }_{\text {ads }}\right)$ is calculated following the equation

$$
\mathrm{K}=-\log \mathrm{C}_{\mathrm{H}_{2} \mathrm{O}}-\left(\frac{\Delta \mathrm{G}_{\mathrm{ads}}^{\circ}}{2.303 \mathrm{RT}}\right)
$$

The Langmuir's plot (Fig. 3) for tested inhibitor system gave a straight line which indicates the monolayer adsorption. From the intercept of the plot the values of $\mathrm{K}_{\mathrm{ads}}$ were obtained which is used to calculate the values of $\Delta \mathrm{G}^{\circ}{ }_{\text {ads }}$ (Table 3). In general, $\Delta \mathrm{G}^{\circ}$ ads values $\leq-20 \mathrm{kJmol}^{-1}$ are suggestive of physisorption, while beyond this value $\left(-40 \mathrm{kJmol}^{-1}\right)$ is said to be chemisorptions ${ }^{23}$. The calculated values of $\Delta \mathrm{G}^{\circ}{ }_{\text {ads }}$ for GEG, 3MDPP and binary mixture are in the range of 16.63-17.33, 15.66-15.77 and 18.37$19.22 \mathrm{kJmol}^{-1}$ respectively (Table 3 ). These results confirm the spontaneity of the reaction and the inhibitor molecule are adsorbed through physisorption process.

\section{Tafel's polarization studies}

The corrosion inhibition behavior of GEG, 3MDPP and binary mixture towards the MS corrosion in $1 \mathrm{~N} \mathrm{HCl}$ were studied using Tafel's method and the parameters $i_{\text {corr }}, E_{\text {corr }}, b_{a}$ and $b_{c}$ were derived. Analysis of Table 4 clearly shows that $i_{\text {corr }}$ value decreases with increasing the concentration of GEG whereas 3MDPP shows minimum $\mathrm{i}_{\text {corr }}$ value. The binary mixture gives very least $\mathrm{i}_{\text {corr }}$ value. Generally, solution inhibited by cathodic or anodic compounds show higher $\mathrm{E}_{\text {corr }}$ value and mixed type inhibitor show lower $\mathrm{E}_{\text {corr }}$ value when compare with uninhibited solution ${ }^{24,25}$. $E_{\text {corr }}$ values for the studied inhibitor system is low and it can be viewed as mixed type, predominantly controlled by anodic reaction.
Table 3: Adsorption parameters for GEG, 3MDPP and binary mixture on MS in $1 \mathrm{~N} \mathrm{HCl}$

\begin{tabular}{lcccc}
\hline Inhibitor & $\mathrm{T}(\mathrm{K})$ & Intercept & $\mathrm{K}\left(\mathrm{mol}^{-1}\right)$ & $\begin{array}{r}-\Delta \mathrm{G}^{\circ} \\
\left(\mathrm{kJ} \mathrm{mol}^{-1}\right)\end{array}$ \\
\hline GEG & 303 & 0.0755 & 13.2425 & 16.63 \\
& 313 & 0.0942 & 10.6143 & 16.6 \\
& 323 & 0.0876 & 11.4094 & 17.33 \\
3MDPP & 303 & 0.1061 & 9.4221 & 15.77 \\
& 313 & 0.1322 & 7.5637 & 15.72 \\
& 323 & 0.1627 & 6.1451 & 15.66 \\
Binary mixture & 303 & 0.0379 & 26.3775 & 18.37 \\
& 313 & 0.0345 & 28.9818 & 19.22 \\
& 323 & 0.0543 & 18.4049 & 18.61 \\
\hline \multicolumn{4}{c}{ GEG }
\end{tabular}
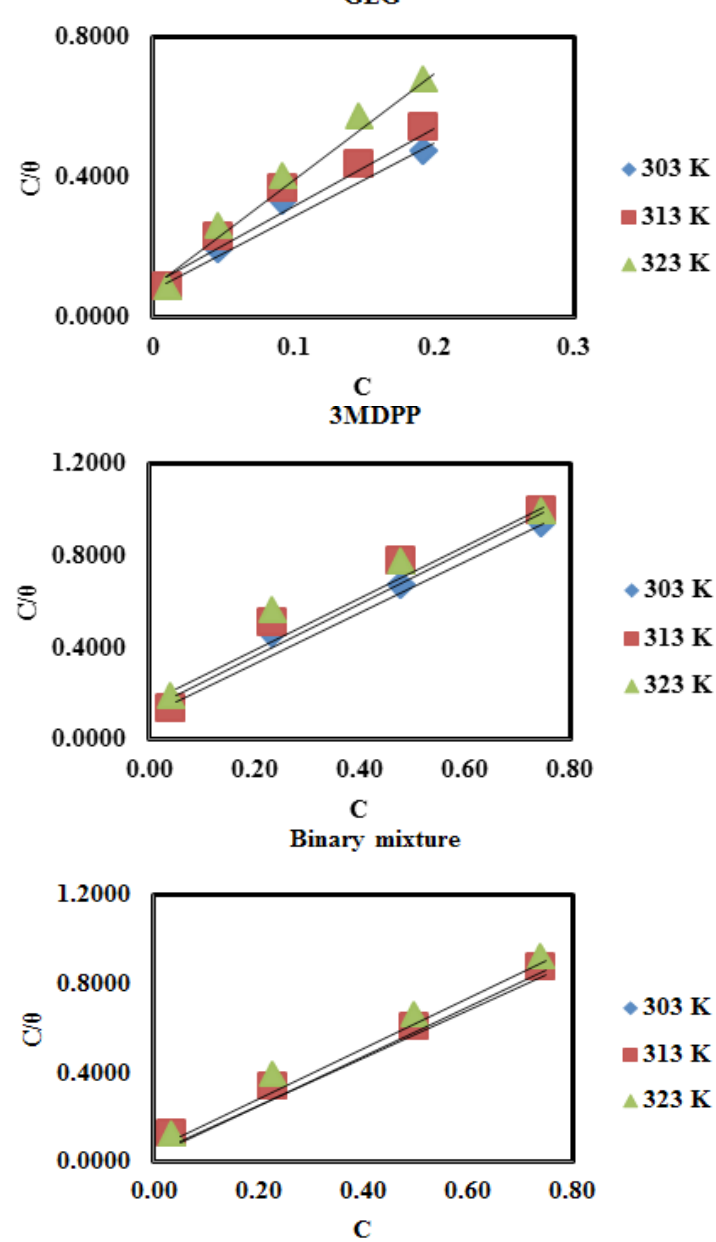

Fig. 3. Langmuir's plots for GEG, 3MDPP and binary mixture on $\mathrm{MS}$ in $1 \mathrm{~N} \mathrm{HCl}$

\section{Impedance studies}

It is one of the most suitable method to predict the formation of film/layer onto the metal surface. The impedance studies were performed 
to derive $R_{c t}$ and $C_{d l}$ values for $M S$ in $1 \mathrm{~N} \mathrm{HCl}$ in the presence of GEG, 3MDPP and binary mixture (Table 5). Their corresponding Nyquist plots are shown in Fig. (5). Analysis of data clearly reveals that the value of $R_{c t}$ increases and $C_{d}$ value decreases in the presence of tested inhibitor systems. The influence is more pronounced in the case of binary inhibitor system. This may be due to the formation of week hydrogen bonding between 3MDPP and GEG molecule. Due to large molecular size of the GEG pushes the already adsorbed 3MDPP close to the MS surface which decreases the $C_{d l}$ values and increases inhibition efficiency ${ }^{26}$.

Table 4: Polarization parameters for GEG, 3MDPP and binary mixture on MS in $1 \mathrm{~N} \mathrm{HCl}$

\begin{tabular}{lccccc}
\hline Inhibitor & $-\mathrm{E}_{\text {corr }}(\mathrm{mV} / \mathrm{SCE})$ & $\mathrm{i}_{\text {corr }}\left(\mathrm{mA} / \mathrm{cm}^{2}\right)$ & $\mathrm{b}_{\mathrm{a}}(\mathrm{mV} / \mathrm{dec})$ & $\mathrm{b}_{\mathrm{c}}(\mathrm{mV} / \mathrm{dec})$ & $\mathrm{IE}(\%)$ \\
\hline Blank & -0.477 & 0.001612 & 0.1472 & 0.0785 & \\
10 ppm GEG & -0.479 & 0.001312 & 0.1403 & 0.0773 & 18.61 \\
50 ppm GEG & -0.476 & 0.00047 & 0.1178 & 0.0622 & 70.84 \\
100 ppm GEG & -0.473 & 0.000419 & 0.1176 & 0.0633 & 74.00 \\
150 ppm GEG & -0.475 & 0.000239 & 0.1044 & 0.0576 & 85.17 \\
200 ppm GEG & -0.491 & 0.000186 & 0.1101 & 0.0815 & 88.46 \\
500 ppm 3MDPP & -0.360 & $6.72 E-05$ & 0.1540 & 0.1136 & 95.83 \\
Binary mixture & -0.490 & $5.09 E-05$ & 0.1137 & 0.0847 & 96.84 \\
\hline
\end{tabular}
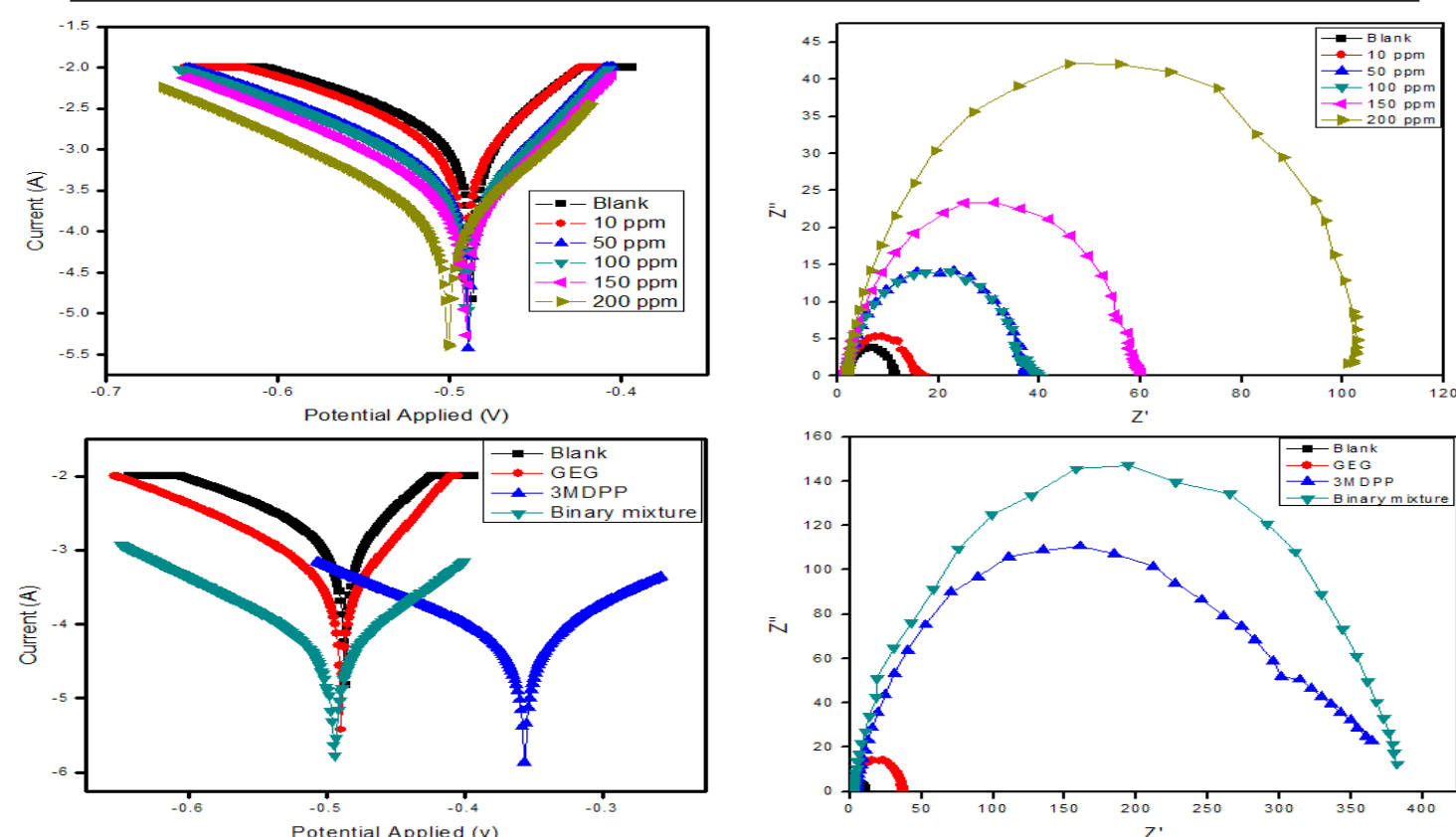

Fig. 4. Tafel's plots for GEG and optimum concentration of GEG, 3MDPP and binary mixture

Table 5: Impedance parameters for GEG, 3 MDPP and binary mixture on MS in $1 \mathrm{~N} \mathrm{HCl}$

\begin{tabular}{lccc}
\hline Inhibitor & $\mathrm{R}_{\mathrm{ct}}\left(\Omega \mathrm{cm}^{2}\right)$ & $\mathrm{C}_{\mathrm{dl}}(\mu \mathrm{F} \mathrm{cm}-2)$ & $\mathrm{IE}(\%)$ \\
\hline Blank & 7.05 & 61.3 & \\
10 ppm GEG & 11.36 & 86.6 & 37.94 \\
50 ppm GEG & 31.3 & 77.7 & 77.47 \\
100 ppm GEG & 37.8 & 82.1 & 81.34 \\
150 ppm GEG & 51.62 & 78.1 & 86.34 \\
200 ppm GEG & 92.66 & 69.6 & 92.39 \\
500 ppm 3MDPP & 268.99 & 20.7 & 97.37 \\
Binary mixture & 322.47 & 51.6 & 97.81 \\
\hline
\end{tabular}

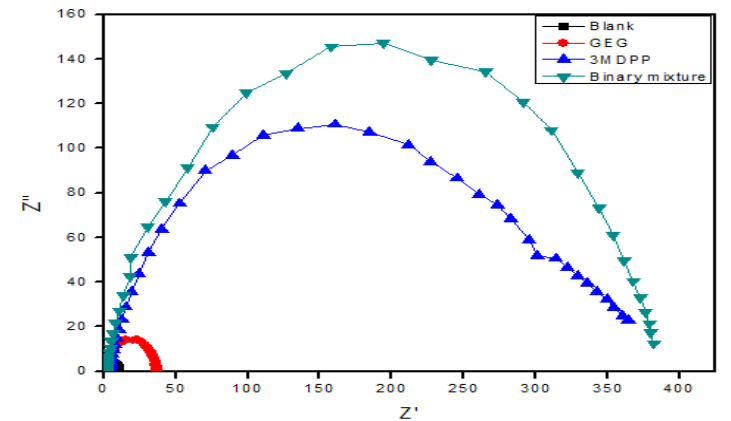

Fig. 5. Nyquist plots GEG and optimum concentration of GEG, 3MDPP and binary mixture

\section{CONCLUSION}

GEG and 3MDPP are very good corrosion inhibitors for dissolution $\mathrm{MS}$ in $1 \mathrm{~N} \mathrm{HCl}$ and their inhibiting ability increases with increasing its concentration but decreases with rise in temperature.

Binary combination of GEG and 3MDPP shows excellent inhibiting potency and also prevent the metal dissolution at higher temperature. 
- The value $S_{\theta}$ for binary mixture is $>1$ confirms the synergism existing between GEG and 3MDPP.

- The calculated values of $\mathrm{E}_{\mathrm{a}}{ }^{*}, \Delta \mathrm{H}^{*}$ and $\Delta \mathrm{G}_{\text {ads }}^{\circ}$ for GEG, 3MDPP and binary mixture conclude a physisorption mechanism and it obeys Langmuir's isotherm.

- Tafel's polarization study reveals that tested inhibitors act as mixed type.
Increasing $R_{c t}$ value and decreasing $C_{d l}$ value in the presence of GEG, 3MDPP and binary mixture confirms the formation of film on MS.

\section{ACKNOWLEDGMENT}

The author and co-authors are thankful to Principal and Secretary of PSG College of Arts and Science, Coimbatore for providing the lab facilities to carry out the research work.

\section{REFERENCE}

1. Paul Ocheje Ameh. Inter. J. Met., 2015, 2015, 1-13.

2. Paul Ocheje Ameh. Inter. J. Mod. Che., 2012, 2(1), 28-40.

3. Nnabuk Okon Eddy.; Udo J. Ibok.; Paul O. Ameh.; Nsor O. Alobi.; Musa M. Sambo. Chem. Eng. Comm., 2014, 201, 1360-1383.

4. Anjali Peter.; Sanjay K. Sharma.; Ime Bassey Obot. J. Anal. Sci. Tech., 2016, 7(26), 1-15.

5. Paul Ocheje Ameh.; Nnabuk Okon Eddy. Res. Chem. Inter. Med., 2014, 40, 2641-2649.

6. Paul Ocheje Ameh.; Ladan Magaji:;Takuma Salihu. Afric. J. Pu. App. Chem., 2012, 6(7), 100-106.

7. Umoren, S.A.; Ekanem, U.F. Chem. Eng. Comm., 2010, 197, 1339-1356.

8. Umoren, S.A.; Obot, I.B.; Ebensob, E.E.; ObiEgbedi. N.O. Desal., 2009, 247, 561-572.

9. David E. Arthur.; Adebiyi Adedayo.; Gerald Igelige.; Edwin Ogwuche. Amer. Chem. Sci. J., 2014, 4(6), 847-854.

10. Nnabuk O. Eddy.; Anduang O. Odiongenyi.; Paul O. Ameh.; Eno E. Ebenso. Int. J. Electrochem. Sci., 2012, 7, 7425 - 7439.

11. HamzaBentrah.;Youssoul Rahali.;Abdelouahad Chala. Corr. Sci., 2014, 82, 426-431.

12. Mohammad Mobin.; Marziya Rizvi. Carbo. Poly., 2016, 136, 384-393.

13. Mobin, M.; Alam Khan, M. J. Dis. Sci. Tech., 2013, 34, 1496-1506.
14. Umoren, S.A.; Ebenso, E.E. Pig. Res. Tech., 2008, 37(3), 173-182.

15. Brindha, T.; Mallika, J. Orient. J. Chem., 2015, 31(2), 741-752.

16. Glory Tharial Xavier.; Brindha Thirumalairaj.; Mallika Jaganathan. Inter. J. Corros., 2015, 2015, 1-15.

17. Malanvizhi Manickam.; Dheenadhayalan Sivakumar;; Brindha Thirumalairaj.; Mallika Jaganathan. Adva. Phy. Chem., 2016, 2016, 1-12.

18. Balasubramanian, M.B.; Padma, N. Tetrahed., 1963, 19(12), 2135-2143.

19. Noller, C.R.; Baliah, V. J. Ameri. Chem. Soci., 1948, 7O(11), 3853-3855.

20. ASTM practice standard G-31, "Standard practice for laboratory immersion corrosion testing of metals", ASTM International, 2004.

21. Selvaraj, K.; Manjula, N.; Mallika, J. Trans. Met. Chem., 2001, 26, 224.

22. Aramaki, K.; Haghwara, M.; Nishihar, H.; Corro. Sci., 1987, 27, 487.

23. Shukla, S.K.; Ebenso, E.E. Inter. J. Electrochem. Sci., 2011, 6, 3277.

24. Umoren, S.A. Port. Electrochim. Acta., 2009, 27(5), 565-577.

25. Li, W.H.; He, Q.; Zhang, S.T.; Pei, C.L.; Hou, B. J. App. Electrochem., 2008, 38, 289.

26. Goudarzi, N.; Peikari, M.;Zahiri, M. R.; Mousavi, H. R. Arch. Metal. Mat., 2012, 57, 845. 